\title{
Moral development in sports at school age: Towards a fair play behaviours typology expressed in the White Card (Tarjeta Blanca) programme
}

\author{
Gema Ortega Vila ${ }^{1}$, Javier Durán González ${ }^{1}$, Jorge Franco Martín ${ }^{1}$, Javier Giménez Fuentes-Guerra ${ }^{2}$, Pedro Jesús \\ Jiménez Martín ${ }^{1}$, Concepción Jiménez Sánchez ${ }^{1}$, Manuel Abad Robles ${ }^{2}$ and María José Camacho-Miñano ${ }^{3}$ \\ 1 Universidad Politécnica de Madrid, Facultad de Ciencias de la Actividad Física y del Deporte -INEF, 28040, Madrid, Spain \\ 2 Universidad de Huelva, Spain \\ 3 Universidad Complutense de Madrid, Spain
}

Received 09 October 2014 - Accepted 26 January 2015

\begin{abstract}
This paper aims to contribute to a better understanding of the moral development in sports at school age. A fair play behaviours typology has been developed, arranged into five stages of ethical progress and performed by young athletes within the White Card programme at the Fundación Real Madrid (FRM) basketball schools. In order to ascertain its validity, descriptions of the behaviours were submitted to the coaches at the FRM $(n=18)$, and a group of experts in sports and values from the actual $\operatorname{FRM}(n=6)$ in order to rate them on a scale from 1 to 5 depending on the moral value they attribute. The result obtained confirm, with few exceptions, the five proposed stages of progression.
\end{abstract}

Key words: Fair play, values, ethics, sports initiation

Résumé. Le développement moral dans le sport à l'âge scolaire : Vers une typologie des conduites de fairplay exprimées dans le programme Carton Blanc (Tarjeta Blanca).

Ce travail a pour objet de contribuer à une meilleure compréhension du développement moral dans le sport à l'âge scolaire. Nous avons elaboré une typologie de conduites de fair play ordonnées en cinq niveaux de progression éthique et réalisées par de jeunes sportifs des écoles de basket de la fondation Real Madrid (FRM) dans son programme Carton Blanc (programa Tarjeta Blanca). Pour vérifier sa validité, les descriptions des conduites on été présentées aux entraîneurs de la FRM $(n=18)$ et à un groupe d'experts en sport et valeurs de la FRM $(n=6)$ elle-même pour les faire évaluer dans une échelle de 1 à 5 en fonction du mérite moral accordé. Le résultat obtenu, sauf pour de légères exceptions, confirme les cinq niveaux de progression proposés.

Mots clés : Fair play, valeurs, éthique, initiation sportive

\section{Introduction}

This paper is the product of different lines of study and research, the first of which was the work of Lawrence Kohlberg (Hersh, Raimer, \& Paolitto, 1984; Kohlberg, 1976; Kohlberg, Levine, \& Hewer, 1983) stands out. His stages of moral development inspire a large part of the major research on moral development and sports (Arnold, 2001; Bredemeier, 1994; Bredemeier, \& Shields, 1984; Bredemeier, Weiss, Shields, \& Cooper, 1987; Cecchini, Fernández, González, \& Arruza, 2008; Fraile, 2010; Gimeno, 2003; Gutiérrez, 2003; Gutiérrez, \& Vivó, 2005;
Hellison, 1995; Jiménez, 2011; Ruiz, et al., 2006; Shields, \& Bredemeier, 1994).

It is also necessary to mention the Rokeach Value Survey (1973), which has allowed us to develop a theoretical model for classifying values in sports (Durán, 2013), with special emphasis on the difference between instrumental and terminal values. Instrumental values are those that can be attributed to both good and bad causes: teamwork, cooperation, leadership, discipline, commitment, desire for self-improvement, motivation, willpower, persistence, achievement, success, self-control of impulses, health, etc. They are enormously useful for sports groups, 
and can without any doubt also be so for criminal groups. Conversely, terminal or ethical values are those that bring us closer to the essence of what is good and fair. They can be considered as superior to the instrumentals values, and it is precisely for this reason it is difficult to attribute them to bad causes. These terminal or ethical values can be subdivided into two categories: those of an emotional nature reflecting our ability to sympathise with others and emotionally identify with them (respect, empathy, compassion, humanity, mercy, solidarity); and those related to helping others through self-sacrifice, which involve not only the concern towards others like us, but helping and supporting them while sacrificing our own interests (these values include honesty, integrity, selflessness, altruism and generosity).

Equally, terminal or ethical values can be considered superior to the instrumental values because they are universal. They help people evolve in two senses: from selfinterest to being concerned about the interest of others (from selfishness to unselfishness); and from being concerned about the interest of our own people ("own tribe", family, friends) to being concerned about the interests of others (wherever they may come from). Ultimately they are values that extend the sense of loyalty, from the mentality of being only involved with people of your kind, to a type of universal loyalty, binding us to every human being. One of the keys to the evolution of mankind is to widen the circle of compassion to all human beings. (Darwin, 1871).

Schwartz \& Bilsky (1987) revisit this idea when they differentiate between the dominion of benevolence (focused on the concern for the well-being of people in our day-to-day interaction), and the concept of universalism (when we are able to transcend the narrow limits of the reference group to reach a maturity that facilitates understanding, acceptance, tolerance and protection of the well-being of all people and of nature). These same authors also note the existing contrast between achieving success and prosocial power, i.e. between pursuing one's own interest, and self-sacrifice to promote the well-being of others.

If we apply this logic to sports, we can claim that although sport facilitates the instrumental values that are useful in achieving good sports results whilst improving our personal (motivation, effort and self-improvement, etc.) and collective performance (team work, cooperation, etc.), thus making us more competitive and helping us to play better and to win against our opponents, it does not, however, encourage the terminal values in terms of at developing and enhancing our ethical or moral sensitivity towards others. Perhaps with my group, but little, if at all, with others. The more we advance in terms of values, when progressing from instrumental to terminal values, the more difficult it is to find them and work on them in the context of competitive sports.

It is relatively easy to understand why competitive sport does not contribute to ethical and moral progress, which we understand is the transition from being concerned about yourself or your friends/family, towards caring about others. Within a competitive context with a sole winner, in which players are fighting to achieve one goal, whilst knowing that only one of the two can achieve victory, it is very difficult with athletes to instil the notion of being concerned about the feelings of others (challengers, opponents or rivals); it is even harder still to convey altruistic attitudes and behaviours at the highest ethical level where one makes sacrifices for the well-being of the others. We could say they are incompatible or contradictory realities. Fraleigh (1984) had already pointed out that moral standards of a social nature were superior to self-interest, and that competitive sports have essentially always been a more self-centred activity than an activity for helping others.

Bredemeier (1994) maintains that within the context of sport, the lower-level reasoning often prevails, the one which defends the achievement of victory to justify any type of behaviour, even an aggressive one. With the usual argument that "the others do the same", they usually take a stance in which self-interest is placed above common interest.

It is precisely because of these difficulties involved in sport when it comes to transmitting values to its practitioners, that all sports at school age should take great care to observe this educational guide and sense of ethics in their approach (Figley, 1984; Wandzilak, 1985).

On the basis of these schools of thought on the evolution of moral development and the hierarchy of values in sports, and considering that in sports at school-age, a basically educational and morally oriented development objective of young practitioners should always prevail, a typology of sportsmanship behaviours has been designed reflecting a moral evolution in sports contexts, which also respond to real fair play behaviours established by young athletes within the Fundación Real Madrid (FRM) White Card programme.

\section{The Fundación Real Madrid "White Card" programme}

This programme is part of the project "Por una Educación REAL: Valores y Deporte" (For a REAL Education: Values and Sport), which has been in development since the 2008-2009 season at the FRM basketball schools and is developed with children aged between 9 and 15 . One of the essential features of this project has been the development of a competition model, which prioritises its strictly sport-focused educational purpose, while minimising the negative impacts that any sporting competition may bear.

The White Card programme was launched during the 2010-2011 season, and consists of awarding a white coloured card to those players who have shown good conduct in the FRM internal tournament. The main objective is to encourage young athletes to behave sportingly 
and to internalise their attitudes and honest behaviour to the extent they display them habitually and spontaneously (Ortega, et al., 2013). Another objective, which is no less important, is to strengthen the educational sensitivity of teachers-coaches, by encouraging them to find merits and values in each and every one of the boys and girls they train. In short, this is a programme about directing the focus and attention of the entire sport infrastructure (athletes, teachers-coaches, families and those in charge) towards strengthening behaviours of sportsmanship and fair play, rather than penalising or punishing the negative ones.

After the match, the athletes leave a written public record of the behaviour for which he/she has been awarded on the cards intended for this purpose. These detailed descriptions on behaviours constitute exceptional information about fair play and sportsmanship behaviours at those ages.

The involvement and commitment of the coaches in implementing this strategy have been essential to the success thereof. At the beginning of the programme, there was only a list of ten sportsmanship behaviours which, by way of example, might have been considered to deserve said Card (Ortega, et al., 2014). As time progressed, White Cards were awarded based on other behaviours that were also deemed worthy of such recognition besides those on the initial list. This development has been encouraging throughout work meetings with the coaches through discussion groups, as they pointed out that they were missing greater criteria objectivity when assessing the behaviours that should be rewarded. By way of selfcriticism, they even recognised they were not all applying such positive support in the same way. They understood that the programme would become more efficient if they made the criteria clear and more consistent as to when to display the white cards (Ortega, et al., 2013).

Therefore, the purpose of this study is to cover the deficiency the coaches themselves pointed out, with its main objective being the development of a sportsmanship behaviours and fair play categorisation for these young athletes at school age, ranking them in ethical and moral ${ }^{1}$ value progression levels or lines, based on their actual behaviour within the White Card programme at the FRM basketball schools. This is a novel study that draws for the first time an evolutionary map of the different moral development levels or stages achieved by young athletes in practical sports situations.

\section{Material and method}

From all the descriptions of white card rewarded behaviours (75 in the 2010-2011 season, 308 in the 2011-2012 season and 438 in the 2012-2013 season), a typology or categorisation of sporting behaviour and fair

\footnotetext{
${ }^{1}$ In this article we are using the concepts of ethics and morality as synonyms.
}

play ranking according to their moral value has been developed as a summary.

With the aim of verifying and comparing the validity and consistency of the proposed typology, the coaches at the FRM basketball schools, as well as a group of experts from said Foundation, were requested to assess such sporting and fair play behaviours according to moral merit granted by them. The list of behaviours was sent to them by email in March 2013.

\subsection{Participants}

Initially, the total sample number of coaches was 18. Four of them did not respond to the invitation to participate in the study, and so the final sample was made up of a total of 14 coaches ( 8 men and 6 women), aged between 21 and 36 years, with coaching experience at the FRM basketball schools with children ranging from 1 to 12 years.

The same was done with a group of experts, including of six specialists in the educational realm of sports values that make up the FRM's own values task force. They are recognised experts in education and research in the field of sports education and social values; all of them agreed to participate in the study.

\subsection{Instrument}

For the moral evaluation of sporting and fair play behaviours by both the coaches and the experts, they received a list of all those selected behaviours that represent the five levels of moral progress ${ }^{2}$. This list was in a disordered manner and without any grouping by levels in order to not bias the answers. They were requested to value each behaviour on a scale from 1 to 5 depending on the moral merit given, 1 being the lowest moral value and 5 the highest moral value. The coaches were also invited to add other behaviours which, in their personal opinion, also deserved such recognition. It is precisely for this reason that we can see in the results table at the end that in the case of the experts the behaviours added by the coaches appear. Below you can find the list of behaviours grouped into different levels of moral progress.

Level 1- Good personal attitude. Individual behaviours, attitude and personal effort, represent the most basic level of moral development, since they do not extend to social aspects such as concern for others. The two behaviours that make up this level were:

(i) Always makes an effort in training sessions, tries to exceed himself/herself, displays a good attitude.

(ii) Fights and exerts himself/herself until the end of the game, even if with an unfavourable score.

${ }^{2}$ If levels are ordered based on their moral value, behaviours that make up each level are not ranked according to its merit. 
Level 2- Respect for authority and rules. The second level is marked by respecting authority (coach, referee) and the rules. The behaviours that make up this level were:

(i) Obeys the rules, advice and corrections of the coaches.

(ii) Respects the referee's decisions.

(iii) Greets and congratulates the referees at the beginning and at the end of the games, no matter if their team has lost or won.

(iv) Makes fair decisions, without favouring his/her own team $^{3}$.

(v) Asks for substitutions so that other team members can play too ${ }^{4}$.

Level 3- Concern for their own kind (own team). The third level marks the beginning of concern for others, starting with team members. The behaviours that made up this level were:

1. Cares for and helps teammates.

2. Promotes teamwork by passing the ball; is not selfish. (a) Helps non-scoring teammates to score.

3. Always encourages his/her teammates even when they fail.

4. Greets and congratulates teammates at the beginning and at the end of the game, no matter if their team has lost or won.

Level 4- Concern for others (rivals, opponents). A very significant advance in the moral development of athletes occurs when their concern is not only focused on their own teammates but also the players on the opposing team. The behaviours of this level were:

(i) Greets and congratulates the rival team at the beginning and at the end of the game, no matter if their team has lost or won.

(ii) Apologises to rival team players when fouling and helps them to get up.

(iii) Celebrates goals and triumphs respectfully and restrainedly, avoiding overly exalted or provocative gestures towards the rival team.

(iv) Is able to recognise the merits of the rival team, by applauding when the rival team makes a good shot.

Level 5- Helps others through self-sacrifice. The highest level in the moral development of athletes would occur when they act in a way they would not only help the rival team players and opponents, but when such assistance involves self-sacrifice, at his/her own expense and the expense of his/her own team. These behaviours display values of highest ethical level such as "honesty" and "altruism" defined as "diligence in seeking the well-being

3 At the FRM internal competition until the age of 12 , the athletes themselves are responsible for refereeing.

4 At the FRM internal competition, all team members play for a similar amount of time, so this behaviour reflects a respect for the rules rather than altruistic behaviour. of others even at one's own expense" (RAE, 1992). The behaviours of this level were:

(i) Recognises his/her own faults (e.g., by raising a hand) without waiting for the referee to point it out.

(ii) Helps an injured rival team player without being concerned about missing an opportunity.

(iii) Is able to point out when the referee has made a mistake to his/her team's benefit (e.g., recognising own faults though they went by unnoticed, or faults wrongly designated to the rival team).

\subsection{Data analysis}

We calculated the average scores for moral ratings assigned by coaches and experts to each of the sportsmanship behaviours as well as the average score obtained by the set of behaviours which make up each level of moral progress. We are aware that statistically we may not interpret a qualitative variable as we would a quantitative one, however, for our purposes the averages provided more useful information than the medians.

\section{Results}

Table 1 shows the average score obtained by the set of behaviours that make up each level of moral progress as well as score averages obtained for each of the behaviours within each level.

When comparing the average scores by levels of moral progress, it can be observed that the average score obtained by sports and fair play behaviours of different levels, increases as they move within their degree of moral progress. These results generally confirm the established typology. In the case of the experts, the progress based on levels is fully confirmed; while there is a slight exception in the case of the coaches (level 2 displays a slightly lower rating than level 1, whereas levels 3 and 4 show an identical rating). Within this moral progress typology, level 5, which takes into account behaviours related to helping rival teams through self-sacrifice, obtains the maximum rating from both experts (4.7) and coaches (4.2). That is, those honest and altruistic behaviours in the context of sports competitions are considered by the participants on a higher moral level. The next rating level obtained is for both groups level 4 (concern for rivals and opponents); although the coaches rate it with the same score as for level 3 , i.e. they rate a concern for the rivals as equal to a concern for their own team players (3.95 average score in both cases). However, the group of experts rates helping rivals as significantly higher (4.45) than own teammates (3.9). The two higher levels 4 and 5 have been rated significantly higher by the experts than by the coaches.

The two lower levels within the typology of moral progress are those obtaining a lower score. At these levels, the experts also confirm the established typology, 


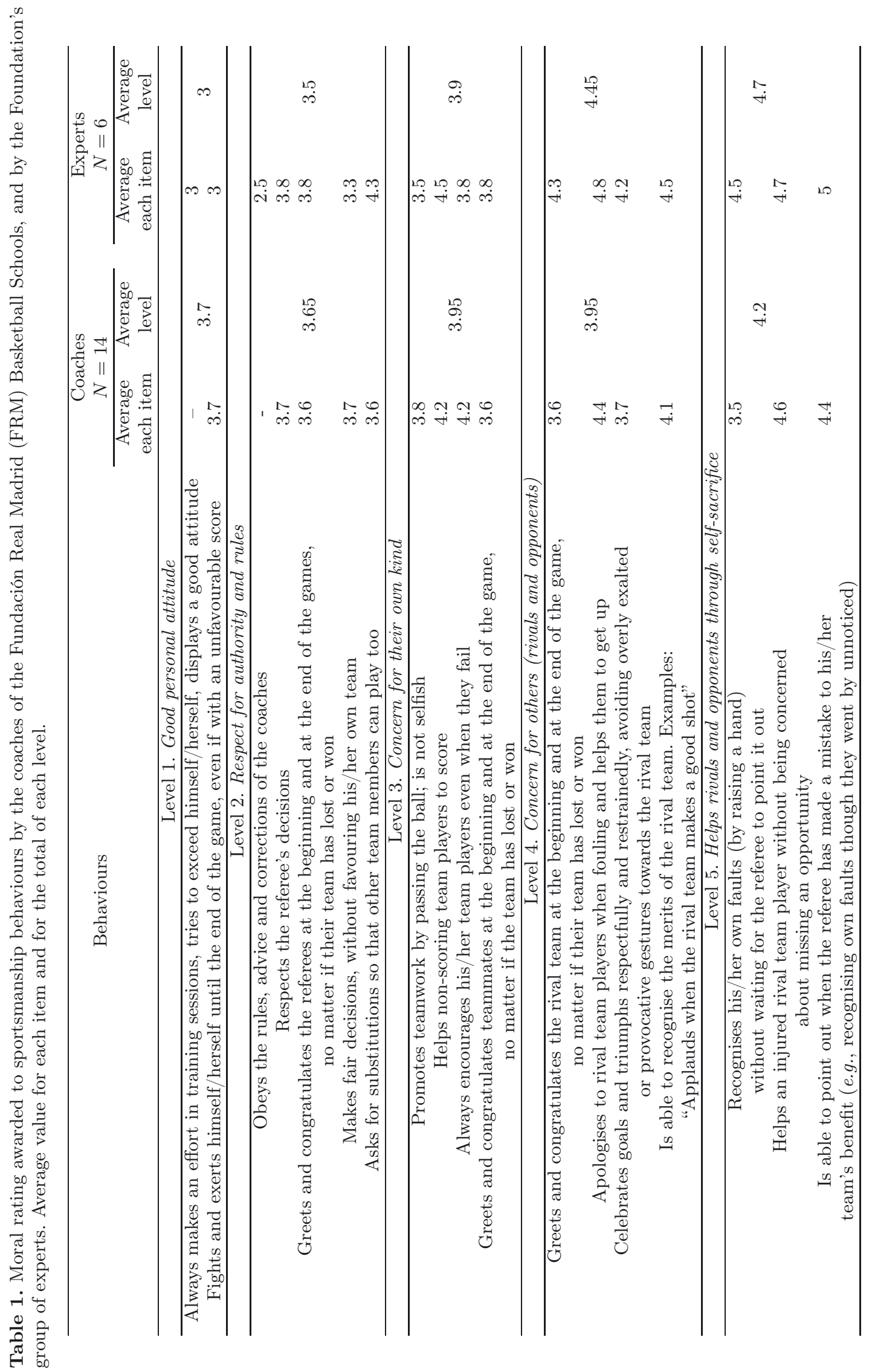


since they rate the lowest level 1 "good personal attitude" (3 points), then level 2 "respect for authority: coach, referee and the rules" (3.5 points). The only exception to the typology occurs with the coaches rating level 1 (3.7) slightly above level 2 (3.65). Level 1 has been the only one rated higher by the coaches (3.7) than by the experts (3).

Next, we analysed the results of the most prominent items within each level. With regard to level 1, good personal attitude, it is to be noted that the questionnaire given to the experts had a second item: "Always makes an effort in training sessions, tries to exceed himself/herself, displays a good attitude", which allows us to verify that they rate a good attitude both in training and in games similarly (3).

Level 2: Respect for authority and rules, the average ratings awarded by the coaches for each item, display little variability ranging between 3.6 and 3.7 points. The ratings of the experts have been slightly disparate in two of these behaviours: a lower rating awarded to "makes fair decisions without favouring his/her own team" (3.3); and a higher rating awarded to "asks for substitutions so that other team members can play too" (4.3). The rating regarding the new behaviour included in the questionnaire given to experts "obeys the rules of the coaches" was quite low (2.5).

Level 3: Concern for their own kind (own team) stands out due to its high moral rating from both groups (coaches and experts) attributed to "helps non-scoring teammates to score" (4.2 and 4.5 respectively). The next best rated item: "Always encourages always his/her teammates even when they fail" has received a better rating from the coaches (4.2) than from the experts (3.8). Promoting team spirit and the final goodbyes to teammates was given a slightly lower rating.

Level 4: Concern for others (rivals, opponents); the best rated behaviour by both the coaches and the experts has been "apologises to rival team players when fouling and helps them to get up" ( 4.4 and 4.8 respectively). This next best score was given to "is able to recognise the merits of the rival team" (4.1 and 4.5 respectively). Greeting the rival team players and restrained celebrations generally exhibit somewhat lower ratings, though this is rated higher by the experts. You can see that the expert ratings awarded to these four behaviours are higher than those of the coaches.

At Level 5, Helps rivals and opponents through selfsacrifice, we find the two highest ranking behaviours with the highest scores given out of all of those assessed, both by the coaches and the experts. The coaches rated highest the behaviour "helps an injured rival team player without being concerned about missing an opportunity" (4.6), while for the experts it was "is able to point out when the referee has made a mistake to his/her team's benefit" obtaining the highest possible score (5). Already a highly ranked level by the coaches (4.2), the experts ranked it even higher (4.7). The only differing item at this level has been "recognises his/her own faults (by raising a hand) without waiting for the referee to point it out", which received a significantly lower rating from the coaches (3.5) than from the experts (4.5). Though the coaches have given this level a very high score (4.2), the experts rated it even higher (4.7) thus confirming the established typology.

\section{Discussion}

The moral categorisation and typology presented as a hypothesis, have been confirmed in their entirety by the scores awarded by the experts and with slight exceptions in the case of the coaches.

The highest level of ethics, represented by level 5 within this study, and endorsed by the scores awarded by the coaches and expert, is reached with those behaviours that involve helping rival players but that also involve a personal sacrifice (altruism and honesty). They seem to confirm the superiority of the final value "self-sacrifice" (Rokeach, 1973; Durán 2013), and the prosocial and universalist power (Schwartz, \& Bilsky, 1987). Furthermore, in contrast to the legitimate criticism of Fraleigh (1984) and Bredemeier (1994) on how difficult it is to achieve the highest of ethical behaviours in competitive sports, our work demonstrates real examples of the behaviours of young athletes who have achieved this.

The next to score is level 4 which reflects a concern for others (rivals and opponents), however with behaviours that do not involve the sacrifice of one's own interests. In this sense, we would continue in a universalist line (Schwartz \& Bilsky, 1987), but with behaviours that reflect terminal values of emotional identification without personal sacrifice (Durán 2013).

Level 3 "concern for their own kind" which received lower scores, would be referred to as what these authors call the dominion of benevolence (Schwartz, \& Bilsky, 1987).

Levels 1 and 2, which obtained the lowest scores or ratings by coaches and experts, bring together those behaviours reflecting values that we call instrumental (Durán, 2013). They are characterised themselves basically by their potential to move toward good and bad causes without achieving prosocial power (Schwartz, \& Bilsky, 1987).

Another interesting aspect is that the scores awarded by the experts at different levels, reflect a greater heterogeneity than those of the coaches, which display fewer differences. In particular, the difference in score between the expert rating given for levels 1 and 5 is 1.7 , while that of the coaches differs only by 0.5 points between the extreme levels. It may seem that the first group, perhaps due to their greater experience, were better at differentiating between the behaviours, and took better advantage of the assessment scale. The greater the homogeneity in the scores of the coaches seems to follow two different interpretations, depending on their profile. Possibly, the younger and less experienced ones within the programme may be less capable of distinguishing and recognising 
the different moral merits between one set of behaviours than the experts. Moreover, possibly those coaches with greater experience in the programme, and who are very familiar with a competitive system that fosters the good behaviour of their athletes, were more used to these ethical behaviours and therefore gave them a lower rating.

An example of this is seen by the experts who rate "asks for substitutions so that other team members can play too" higher than the coaches do. Given that during the FRM internal competition all team members play for a similar amount of time, the coaches would be aware of this behaviour reflecting a respect for the rules rather than altruistic behaviour as it might have been interpreted by the experts.

Something similar has occurred with the behaviour that displayed the biggest gap in the rating given by coaches and experts: "recognises his/her own faults without waiting for the referee to point them out" (3.5 and 4.5 respectively). The lowest rating awarded by the coaches to these honest behaviours of the athletes might have been due to the fact they are more used to the selfarbitrating system linked to the competition in the early stages where these attitudes of honesty and integrity are learnt as habits and common behaviour. Those experts less accustomed to these behaviours, ranked them higher.

Another behaviour denoting notable differences between the score given by the coaches (3.6) and by the experts (4.3), is that of the players that "greet and congratulate their rivals at the beginning and at the end of the game, no matter if their team has lost or won". Although this behaviour has been included into level 4 "concern for others (rivals and opponents)", the coaches might have interpreted it as an example of certain automated, mechanical sports behaviours; though valuable and worthy they may be considered less moral.

The idiosyncrasy of the internal FRM basketball schools competition, makes it more difficult to distinguish between "their own kind" and others (all the teams are part of a single organisation which makes it difficult to see the other teams as rivals). This may explain why the coaches rate level 3 (concern their own kind) the same as level 4 (concern for others, rivals and opponents). Not so, the experts who have been able to clearly grasp the difference between each level. Surely, by applying this typology in other competitive sport contexts at school age, the dissimilarity will be more than evident.

One of the main challenges the FRM White Card programme and the whole of the project "Por una Educación REAL: Valores y Deporte" proposes, is to provide the coaches with working tools to dynamically transmit values in sport, integrated into the actual activity without losing the excitement, fluidity and fun of the game. For us it was essential to move from conscious and reflective morals to practised morals, being able to go beyond moral judgement or reasoning, on to action and ethical sportsmanship. In short, taking the values from theory to practice. As Lickona (1993) and Lapsley (1992) point out, the key is moral action, not moral judgment. It is well known that although sports offer enormous opportunities for ethical conflicts (Shea, 1978), many moral development programmes in sport still use hypothetical dilemmas (Cantillo, et al., 2005; Fraile, 2010; Sáenz, Gimeno, Gutiérrez, \& Garay, 2012; Wandzilak, 1985). This paper overcomes this issue by investigating and noting the levels of moral development achieved by these young athletes in practical sports situations, i.e., taking into account moral actions and ethical behaviours that occurred during the course of competitions and matches.

However, training sessions also provide ideal situations for working on values from within the actual sport groups: with peers (team players), authority (coach), and rules (internal team rules). If these attitudes are fostered during the week, then they will be reflected in games (with peers taking on the rival players role), with the authority (referee), and the rules (regulation). With ethics and values the same happens as with tactical and technical aspects: the more they are trained during the week, the more they are applied in games. And not only in "easy games" or "rubbish minutes", but in finals and in decisive moments, right when the championship is at stake; it is here where we demonstrate honesty and true principles.

Competitive sport is presented as an extraordinary area to work on interpersonal relationships, first with my own team players, but also with the rival players and opponents. Even the highest ethical level is expressed in those behaviours involving help to rival players but which also carry personal sacrifice: altruism and honesty would be exemplifying values to these behaviours.

\section{Conclusions and future outlook}

Generally, the moral values that coaches and experts have attributed to the analysed behaviours of sportsmanship, confirm the proposed moral typology, recognising a growing merit at the following levels: good personal attitude (level 1), respect for authority and rules (level 2), concern for their own kind (level 3), concern for rival players and opponents (level 4), and helps rivals and opponents through self-sacrifice (level 5).

The typology of sporting behaviour and fair play presented in this paper as a result of practical experience gained in the FRM White Card Programme, is a very valuable tool for improving the programme itself in terms of enhancing efficiency and consistency by delivering these cards. However, its usefulness certainly exceeds the own FRM boundaries; it helps assess the level of ethical and moral development achieved in competitions by the young athletes at school age, and direct teacherscoaches in the task of promoting such evolution. It is a tool that can help combat many of the behavioural issues and the lack of values appearing too often in this type of competition.

Our work overcomes another excessively frequent criticism that these types of programmes receive on the transmission of values in sport, by referring to the lack of 
assessment on the impact that these interventions cause (Sáenz, et al., 2012). It is not only a valuable instrument for assessment but also for promoting the moral development of coaches and parties responsible for the programme.

Among the future work opportunities is the confirmation of the validity of the typology, verifying statistically how many behaviours appear in each level. The logical and consistent thing would be that, if the typology is correct, the higher the moral merit of the behaviours, the fewer of them may be exhibited precisely because of the greater difficulty involved in displaying such behaviours. There should also be a distinction between sportsmanship behaviours according to age, gender and sports.

Given the fact that the analysed sportsmanship behaviours, which have enabled the generation of this typology, have all been made during basketball sessions, it would be necessary to make certain adjustments so that this typology may be generally applied to other sports, like football, which is very much in need of these educational initiatives.

Another project would be to analyse the impact of self-arbitration on ethical and moral development of older athletes. If FRM has applied it only up to the age of 12 so far (here, the games are played without a referee and the players themselves are in charge of referring), now we need to extend this model to higher age groups, starting the experience with an experimental group.

In our opinion, the research line that has the most potential, is the analysis of brief reflections undertaken shortly after finishing a game, when the young players from both teams jointly decide to whom the white card for sportsmanship should be awarded. If until now the responsibility of deciding who was the athlete worthy of such recognition rested exclusively with the teachercoach, who used it as a positive reinforcement for Social Learning (Bandura, 1977), from now on it will be the boys and girls themselves from both teams that will jointly reflect right after the game on whom the prize should go. This means promoting the transition from heteronomy to moral autonomy and structural development (Kohlberg, 1976), empowering them and making them responsible for the white card award process to a much greater extent. These moments of reasoning and ethics-moral-sports debate on the noblest behaviours performed on the court just moments before, seem to be of exceptional value since they allow for the analysis of the development of ethicsmoral-sports argumentation levels by young athletes at school age.

\section{Bibliography}

Arnold, PJ. (2001). Sport, moral development, and the role of the teacher: Implications for research and moral education. QUEST, 53 (2), 135-150.

Bandura, A. (1977). Social learning theory. New Jersey: Prentice-Hall.
Bredemeier, B. (1994). Children's moral reasoning and their assertive, aggressive and submissive tendencies in sport and daily life. Journal of Sport \& Exercise Psychology, 16, $1-14$.

Bredemeier B., \& Shields, D. (1984). The utility of moral stage analysis in the investigation of athletic aggression. Sociology of Sport Journal, 1, 138-149.

Bredemeier B., Weiss, M., Shields, D., \& Cooper, B. (1987). The relationship between children's legitimacy judgments and their moral reasoning, aggression tendencies and sport involvement. Sociology of Sport Journal, 4, 48-60.

Cantillo, J., Domínguez, A., Encinas, S., Muñoz, A., Navarro, F., \& Salazar, A. (2005). Dilemas morales. Un aprendizaje de valores mediante el diálogo. Valencia: Nau Llibres.

Cecchini, J., Fernández, J., González, C., \& Arruza, J.A. (2008). Repercusiones del Programa Delfos de educación en valores a través del deporte en jóvenes escolares. Revista de Educación, 346, 167-186.

Darwin, Ch. (1871). El origen del hombre. Madrid: Edaf, trad. 1982

Durán, J. (2013). Ética de la Competición Deportiva: Valores y contravalores del deporte competitivo. Materiales para la Historia del Deporte, 11, 89-115.

Figley, G. (1984) Moral education trough physical education. QUEST, 36 (1), 89-101.

Fraile, A. (2010). El desarrollo moral en el deporte escolar europeo: un estudio basado en dilemas sociomorales. Estudios Pedagógicos, 35 (2), 83-97.

Fraleigh, W. (1984). The right actions in sport: Ethics for contestants. Champaign, Ill: Human Kinetics.

Gimeno, F. (2003). Descripción y evaluación preliminar de un programa de habilidades sociales y de solución de problemas con padres y entrenadores en el deporte infantil y juvenil. Revista de Psicología del Deporte, 12 (1), 67-80.

Gutiérrez, M. (2003). Manual sobre valores en la educación física y el deporte. Barcelona: Paidós.

Gutiérrez, M., \& Vivó, P. (2005). Enseñando razonamiento moral en las clases de educación física escolar. European Journal of Human Movement, 14, 1-22.

Hellison, D. (1995). Teaching responsibility through physical activity. Chicago: Human Kinetics.

Hersh, R.H., Raimer, J., \& Paolitto, D. (1984). El crecimiento moral: De Piaget a Kohlberg. Madrid: Narcea.

Jiménez, P.J. (2011). Actividad física, deporte y jóvenes en riesgo: Programa de intervención en valores sociales y personales. EAE: Saarbruchen.

Kohlberg, L. (1976). Moral development and behaviour: Theory, research and social issues. New York: Holt, Rinehart and Winston.

Kohlberg, L., Levine, C., \& Hewer, T. (1983). Moral Stages: To current formulation and to response to critics. Basel: Karger.

Lapsley, D.K. (1992). Pluralism, virtues and the postkohlbergian was in moral psychology. In F.C. Power, \& D.K. Lapsley, (Eds.), The challenge of pluralism: education, politics, and values (pp. 169-199). Notre Dame, In: University of Notre Dame Press.

Lickona, T. (1993). The return of character education. Educational Leadership, 51 (3), 5-11. 
Ortega, G., Durán, J., Franco, J., Giménez, J., Jiménez, P.J., \& Jiménez, A.C. (2013). La Tarjeta Blanca de la Fundación Real Madrid: transmitiendo valores a través de la competición. Una discusión de grupo con los entrenadores. In Responsabilidad Social, Ética y Deporte, XII Congreso AEISAD (pp. 233-246). Madrid: Ibersaf Industrial.

Ortega, G., Durán, L.J., Franco, J., Giménez, F.J., Jiménez, P.J., \& Jiménez, A.C. (2014). Competir para compartir. . valores. Madrid: Fundación Real Madrid.

RAE, Real Academia Española (1992). Diccionario de la lengua española (21 ed.). Madrid: Espasa Calpe.

Rokeach, M. (1973). The nature of human values. New York: Free Press.

Ruiz, L. M., Rodríguez, P., Martinek, T., Schilling T., Durán, L.J., \& Jiménez, P.J. (2006). El Proyecto Esfuerzo: un modelo para el desarrollo de la responsabilidad personal y social a través del deporte. Revista de Educación, 341, 933-958.

Sáenz, A., Gimeno, F., Gutiérrez, H., \& Garay, B. (2012). Prevención de la agresividad y la violencia en el deporte en edad escolar: Un estudio de revisión. Cuadernos de Psicología del Deporte, 12 (2), 57-72.

Schwartz, S.H., \& Bilsky W. (1987). Toward a universal psychological structure of human values. Journal of Personality and Social Psychology, 53 (3), 550-562.

Shea, E. (1978). Ethical decisions in physical education and sport. Springfield, Illinois: Charles C. Thomas Publisher.

Shields D., \& Bredemeier, B. (1994). Moral Development and physical activity contexts in action. Champaign, IL: Human Kinetics.

Wandzilak, T. (1985). Values development through physical education and athletics. QUEST, 37 (2), 176-185. 